\title{
Learning from history
}

\author{
David H. Wegman ${ }^{1}$
}

\begin{abstract}
The ways historians assemble primary material from which to learn how industry has failed to protect workers and the environment is changing dramatically. Increasingly, historians focus concern on the evolution of the internet and the demise of paper records. The authors of "Monsanto, PCBs," and the Creation of a "WorldWide Ecological Problem" (2018) are also founders of ToxicDocs.org. This webbased resource provides an entirely new degree of transparency. Readers of their article may look at any document they cite by clicking on the reference. Those with or without expertise in science can now judge these authors' analysis, and much more: entertain new lines of inquiry, ask new questions, obtain new insights, and publish well-documented pieces that offer new knowledge and insight to enrich our understanding, not only of the PCB story, but also industry's general behavior when using or marketing toxic substances.
\end{abstract}

Keywords History $\cdot$ ToxicDocs.org $\cdot$ Primary documents $\cdot$ Searchable $\cdot$ Legal discovery $\cdot$ Public health

History has never been an easy discipline. One difficulty is being able to identify original or reliable sources that accurately describe events, individuals, or motivations. Another is to recognize whether the sources that are available are not circumstantially one-sided, as is suggested by the adage "history is written by the victors." Increasingly, historians are concerned with the evolution of the internet and the demise of written records. Histories that rely heavily on correspondence have offered great insights into individuals and their times (including "The Letters of

David H. Wegman

David_Wegman@uml.edu

1 University of Massachusetts Lowell, Lowell, MA, USA 
John and Abigail Adams" [1] and Galileo's Daughter [2]) but these will no longer be possible with the current trend in electronic communication. Saving correspondence and other historically relevant documents has become increasingly difficult. There is a risk that what is saved (electronically or in hard copy) will not be sufficient or appropriate for historical research. Alternatively, there is the worry that what is preserved in electronic form is the product of this powerful platform that permits everyone to contribute 'facts' as they see them. The glut of information available in 'the cloud' presents a prodigious task for the serious historian of the present.

For historians concerned with the general and workplace environments, there is also some good news from the cloud. A new resource, ToxicDocs.org, has created a way to access previously unavailable, behind the scenes, information on industry decisions concerning their use of hazardous agents. Even before such a resource existed, we had some wonderfully creative and thoughtful histories that inform our understanding of industry behaviors and the consequent impact on workers and their families. In 1991, Martin Cherniack published a comprehensive assessment of one of our nation's hidden tragedies, the acute silicosis epidemic at Hawks Nest, West Virginia during the 1930s [3]. Much historical documentation of that event was destroyed by Union Carbide's crucial deletions of documents "related to work on the tunnel, allegations of silicosis, or the hundreds of legal actions that were brought on behalf of former workers" [3] or literally buried as was the case for many African American workers who were interred in unmarked graves. Cherniack, a physician epidemiologist, went to great effort to find and use what little information had been preserved, including Congressional hearings, legal judgments, and newspaper reports to arrive at his conclusion that almost twice as many workers had died than had been previously reported. Furthermore, Cherniack's systematic and careful examination of the records provided important evidence for Union Carbide's knowing disregard for the health of their workers.

More recently, in 2016, Paul Blanc provided a stunning account of the human consequences of viscose rayon and cellophane production over the last century [4]. Employing his talents as a physician, industrial hygienist, and historian, he used primary sources from the published literature, government documents, advisory committees, and letters to describe the evolution of knowledge about carbon disulfide. Carbon disulfide is an essential ingredient in the manufacture of rayon and cellophane. Blanc documents how, over the course of the twentieth century, medical science slowly learned about the acute and chronic neurologic harm that carbon disulfide caused to the poorly protected workers. The slow pace of learning is documented by quoting from the conflicting arguments put forth by scientists in public and in published documents. Most revealing is the evidence that Blanc accumulates about industry having hired scientists to downplay the health effects of exposures. Even today, he documents how newer evidence of cardiovascular effects is receiving similar treatment by industry consultants.

In both these instances, silica and carbon disulfide, it took historians immense time and effort to track down the many materials necessary to document the devastation that had previously lain hidden. Even the two historians who authored the report on PCBs published in this issue [5] used similar historical investigations in their first collaboration: Deadly Dust: Silicosis and the Politics of Occupational 
Disease in Twentieth-Century [6]. The exciting difference between that original collaboration and their latest is their use of the ToxicDocs.org resource [7]. The introduction to this open, free resource appears in an article published in this journal earlier this year [8]. There, the authors and their computer-savvy colleague, Merlin Chowkwanyun, have gathered millions of pages of documents, converted them into text in machine-readable format and placed them in a searchable database. It is now possible for historians, scientists, and citizens to explore and use previously secret documents about toxic substances.

The website ToxicDocs.org contains documents that have been collected during the discovery process that occurs in tort liability cases in the United States. Its founders constantly update it with materials from newer lawsuits involving many industrial chemicals, including lead, asbestos, silica, and PCBs. Moreover, the curating of these documents (housed at the Mailman School of Public Health of Columbia University) has been carefully considered. The materials are restricted to those gathered from legal discovery efforts, from known sources that can be trusted to provide all discovered documents. The hosts have a clear intent that the resource be as reliable as possible. Even using this cautious approach, they are processing hundreds of thousands of new pages that are being delivered through major lawsuits against Monsanto alone.

Probably, most important is that readers of historical and policy analyses who read the paper published in this issue with its links to each document upon which the authors rely, all of which appear on ToxicDocs.org, or who seek out other materials there, will be able to read primary documents directly, thus permitting a degree of transparency never before available. Now it is up to readers, with or without expertise in science to entertain new lines of inquiry, ask new questions, obtain new insights, and publish well-documented pieces that offer new knowledge and insight that enrich our understanding, not only of the PCB story, but also industry's general behavior when using or marketing toxic substances. Historical research is still going to be very hard work. But it is certainly going to be even more interesting. What ToxicDocs.org offers historians is accessible and previously unavailable information about industry motivations and strategy that has, until now, been hidden behind a curtain.

Finally, it should be noted that Monsanto, PCBs, and the Creation of a "WorldWide Ecological Problem" by Markowitz and Rosner published here [5], is an article by historians appearing in a public health journal. This fact should encourage public health professionals to consider publishing their work in a wider variety of places, where the information may serve a different readership rather than to write only for the chorus.

\section{References}

1. Adams J, Adams A. The letters of John and Abigail Adams. New York: Penguin Press; 2003.

2. Sobel D. Galileo's daughter: a historical memoir of science, faith, and love. London: Bloomsbury Press; 1999. 
3. Cherniack M. The Hawk's nest incident: America's worst industrial disaster. Yale University Press; 1986.

4. Blanc P. Fake silk: the Lethal History of Viscose Rayon. New Haven: Yale University Press; 2016.

5. Markowitz G, Rosner, D. Monsanto, PCBs, and the Creation of a "World-Wide Ecological Problem". J Public Health Policy. 2018. https://doi.org/10.1057/s41271-018-0146-8.

6. Rosner R, Markowitz G. Deadly dust: silicosis and the politics of occupational disease in twentiethcentury America. Princeton: Princeton University Press; 1991.

7. www.toxicdocs.org.

8. Rosner D, Markowitz G, Chowkwanyun MJ. ToxicDocs (www.ToxicDocs.org): from history buried in stacks of paper to open, searchable archives online. J Public Health Policy. 2018;39(1):4-11. https ://doi.org/10.1057/s41271-017-0106-8.

David H. Wegman M.D., M.Sc. is a Professor Emeritus, University of Massachusetts Lowell, MA, USA and Adjunct Professor, Harvard T. H. Chan School of Public Health, Boston, MA, USA. He is a specialist in occupational epidemiology, surveillance, and policy. 